\title{
Historicismo fraco: sobre hierarquias de virtudes e de metas intelectuais*
}

\section{Weak Historicism: On Hierarchies of Intellectual Virtues and Goods}

\author{
Herman Paul \\ h.j.paul@hum.leidenuniv.nl \\ Professor associado \\ Departamento de História, Universidade de Leiden, Holanda \\ Leiden University \\ 95002300 RA - Leiden \\ Holanda
}

\begin{abstract}
Resumo
Este artigo busca reconciliar a sensibilidade historicista em relação à forma como o comportamento intelectualmente virtuoso é moldado por contextos históricos, de um lado, e uma abordagem nãorelativista da pesquisa histórica acadêmica do outro. Para tanto, distingue-se entre hierarquias de virtudes intelectuais e hierarquias de metas intelectuais. A primeira hierarquia rejeita um modelo único de virtuosidade histórica em favor de um modelo que permite significativas variações no peso relativo que os historiadores atribuem às virtudes intelectuais, de modo a obter conhecimento histórico fundamentado. Esta hierarquia situa as bases para tais diferenças não nas preferências ou interesses dos historiadores, mas nas suas situações historiográficas, de maneira que as hierarquias de virtudes são uma função das demandas feitas pelas situações historiográficas (definidas como o intercâmbio de gênero, questões de pesquisa, e estado da arte). Da mesma maneira, a segunda hierarquia concede espaço para que sejam perseguidas várias metas intelectuais, mas afasta o espectro do relativismo ao tratar a compreensão histórica como uma meta intelectual fundamental para a pesquisa histórica e que, por consequência, merece prioridade diante de metas alternativas. A posição daí emergente é classificada como uma forma de historicismo fraco.
\end{abstract}

\section{Palavras-chave}

Epistemologia da virtude; Virtudes intelectuais; Virtudes epistêmicas.

\begin{abstract}
This article seeks to reconcile a historicist sensitivity to how intellectually virtuous behavior is shaped by historical contexts with a non-relativist account of historical scholarship. To that end, it distinguishes between hierarchies of intellectual virtues and hierarchies of intellectual goods. The first hierarchy rejects a one-size-fits-all model of historical virtuousness in favor of a model that allows for significant varieties between the relative weight that historians must assign to intellectual virtues in order to acquire justified historical understanding. It grounds such differences, not on the historians' interests or preferences, but on their historiographical situations, so that hierarchies of virtues are a function of the demands that historiographical situations (defined as interplays of genre, research question, and state of scholarship) make upon historians. Likewise, the second hierarchy allows for the pursuit of various intellectual goods, but banishes the specter of relativism by treating historical understanding as an intellectual good that is constitutive of historical scholarship and therefore deserves priority over alternative goods. The position that emerges from this is classified as a form of weak historicism.
\end{abstract}

Keywords

Virtue epistemology; Intellectual virtues; Epistemic virtues.

Recebido em: 10/6/2016

Autor convidado

* Do original: Weak Historicism: On Hierarchies of Intellectual Virtues and Goods. Journal of the Philosophy of History, v. 6, 369-388, 2012. Traduzido por Arthur Assis e Pedro Caldas. Os tradutores agradecem ao autor e editores do periódico Journal of the Philosophy of History por terem liberado esta tradução e possibilitado sua publicação. 
Imagine dois historiadores a realizarem complexas pesquisas acadêmicas. Uma historiadora trabalha em uma biografia de Leopold von Ranke. O outro historiador participa de um projeto destinado à reconstrução das contabilidades nacionais (isto é, de indicadores abrangentes relativos à produção, receitas e despesas) de vários países europeus no século XIX. Ambos os historiadores enfrentam tarefas assustadoras, mas por diferentes razões. A biógrafa de Ranke se vê confrontada com uma vasta quantidade de literatura especializada abrangendo a juventude de Ranke, a sua formação luterana, a nomeação como professor em Berlim, as tarefas docentes, o seu perfil filosófico, as viagens para os arquivos de Veneza e o seu envolvimento com a Academia Bávara de Ciências e Humanidades. Com base nesta riqueza bibliográfica, a historiadora elabora uma biografia que almeja juntar os fios que perpassam a vida e a obra de Ranke, sem jamais se esquecer de que uma tal obra de síntese não somente pressupõe profunda familiaridade com a bibliografia existente, mas também exige bastante do seu poder imaginativo, da sua inteligência e da sua capacidade de julgar. O segundo historiador, por outro lado, nada tem a sintetizar. No seu recente e emergente campo de pesquisa, toda a atenção está dirigida à busca por informações que permitirão generalização estatística. Mesmo que a agricultura e a pecuária sejam setores econômicos bem documentados, dados precisos sobre a produção da horticultura no século XIX são notoriamente escassos (SMITS; HORLINGS; ZANDEN 1999, p. 59). Felizmente, o segundo historiador tropeçou em algumas contas maravilhosamente detalhadas que 26 foram mantidas por horticultores flamengos. Sua tarefa, então, é apurar deste material dados relevantes relativos à produção e a despesas. Com isso poderá estimar a participação destes produtores no mercado através da comparação com outros horticultores do país, e, com base nisso, poderá também calcular, com o máximo de fiabilidade possível, a contribuição do setor para o produto interno bruto da Bélgica.

Imagine agora que ambos os projetos de pesquisa apareçam como estudos de caso em uma investigação filosófica sobre virtudes intelectuais. Dado que atualmente os especialistas em virtudes epistêmicas estão cada vez mais interessados não somente em formas de conhecimento estritamente vinculadas ao raciocínio lógico-matemático, mas também em complexas formas de compreensão, tais como as exigidas para apreciar Os Irmãos Karamazov, de Dostoievski, ou para perceber as nuances da personalidade de uma outra pessoa, este tipo de experimento não é de todo irreal. Se especialistas em virtudes epistêmicas, tais como Linda Zagzebski, Robert C. Roberts, e W. Jay Wood, argumentam que as virtudes intelectuais são especialmente relevantes para "tipos ambiciosos de conhecimento como descobertas científicas, a compreensão sutil de textos difíceis, [e] autoconhecimento moral" (ROBERTS; WOOD 2007, p. 8), ${ }^{1}$ eles terão motivo para examinar as virtudes intelectuais exercitadas por historiadores que se dediquem a biografias de Ranke ou à pesquisa 
sobre contabilidades nacionais. Imagine então estes filósofos perguntando a si mesmos: que virtudes intelectuais a biógrafa de Ranke e o estudioso dos ganhos da horticultura flamenga precisam pôr em prática para fazerem uma contribuição valiosa para a pesquisa histórica erudita ou acadêmica? Devem eles pôr em prática o mesmo conjunto de virtudes intelectuais, na mesma ordem, e no mesmo grau? Ou, será que devem praticar diferentes tipos de comportamento intelectualmente virtuoso para poderem contribuir para uma melhor compreensão do passado?

Pesquisas recentes no campo da historiografia - aquele em que se estuda como os historiadores estudam o passado - conferiram uma certa urgência a essas questões. Tem-se argumentado que nem todos os historiadores concordam quanto ao que seja um comportamento intelectualmente virtuoso. Vem sendo apontado que diferentes tradições historiográficas - por exemplo, a história econômica tal como praticado pelo estudioso especializado na contabilidade nacional belga do século XIX e a história intelectual representada pela biógrafa de Ranke podem ter percepções diferentes sobre o tipo de comportamento intelectual que os historiadores devem ter. Embora tais percepções tendam a se sobrepor umas às outras, as diferenças entre ambas podem ser suficientemente significativas para nos levar à conclusão de que, em termos empíricos, os historiadores nem sempre são unânimes sobre o que se deve entender como comportamento intelectualmente virtuoso (PAUL 2011a). Além disso, mesmo que os historiadores concordem sobre a importância de virtudes intelectuais como a "precisão", não se pode afirmar de maneira inequívoca o que significa, para eles, ser preciso nas suas pesquisas e nos seus textos. Tais definições dependem, entre outras coisas, do peso relativo que eles atribuem a esta virtude em particular; isto é, de como eles relacionam a precisão com outras virtudes intelectuais, tais como a firmeza, a coragem e a cautela. Esta é a razão pela qual somente descrições densas descrições de virtudes intelectuais sensíveis às particularidades do contexto e da situação do historiador - podem esclarecer o que significa ser intelectualmente virtuoso. ${ }^{2}$ Isto se torna ainda mais evidente quando enfim expandimos o raio da nossa análise para além do mundo acadêmico atual e passamos a incluir historiadores de outros tempos e lugares. Quando nos confrontamos com as práticas historiográficas da China da época da dinastia Han ou dos anos mais remotos do Reino dos Francos, e essas diferem significativamente de tudo aquilo que, hoje em dia, poderia ser reconhecido como erudição histórica, é difícil, quando não impossível, deixar de concluir que aquilo que os historiadores consideram como comportamento intelectualmente virtuoso é, em grande medida, "moldado por contextos históricos" (cf. PAUL 2011a, p. 11).

A questão daí emergente é a seguinte: em que medida estas diferenças que atravessam o tempo e as situações podem ser justificadas? Deixem-

\footnotetext{
2 Isto foi belamente ilustrado pelo balanço contextual ricamente matizado feito por Daston e Galison sobre o que a "objetividade" significou para várias gerações de pesquisadores no fim do século XIX e no início do século XX. Ver Daston; Galison (2007). Concentrando-me aproximadamente no mesmo período, tentei mostrar como virtudes tão apreciadas como a honestidade e a cautela adquiriram significados específicos dependendo, entre outras coisas, de constelações de virtudes nas quais elas supostamente deveriam estar integradas (PAUL 2011b; PAUL 2012).
} 
me esclarecer, logo de início, que uma "justificação", neste contexto, não é um atalho para "justificação epistemológica". Afinal de contas, a justificação epistemológica está centrada nas razões que as pessoas têm para manter certas crenças sobre o mundo. De acordo com William P. Alston, "dizer que é justificado que S. creia em $p$ é dizer que está tudo bem que $\mathrm{S}$ creia em $p$; que isso é satisfatório, está de acordo com o modo como as coisas devem ser, " (ALSTON 1989, p. 83). Ainda assim, no caso dos historiadores que privilegiam certas virtudes intelectuais em detrimento de outras, a questão não é sobre em que medida estes acadêmicos têm justificação para acreditar em certas coisas sobre o passado. Em vez disso, a questão que se coloca é a seguinte: em que medida "é satisfatório e está de acordo com o modo como as coisas devem ser" o fato de os historiadores privilegiarem certas virtudes e não outras nas suas tentativas de contribuir para uma melhor compreensão do passado. A questão que aqui está em jogo não diz respeito a crenças sobre o mundo, mas a comportamentos intelectualmente virtuosos.

Falo de justificação, no entanto, devido às conotações normativas desta palavra. Justificação refere-se a estados de coisa que são satisfatórios; a algo que se considera estar "em ordem", ou a práticas que estão "de acordo com o modo como as coisas devem ser". O termo pressupõe "dever", "obrigação", e "exigência" (PLANTINGA 1993, p. 4). Falar que os historiadores estão justificados ao privilegiarem certas virtudes e não outras, então, é falar sobre a pertinência relativa de uma tal conduta. Isto levanta a questão das razões pelas quais é apropriado que certas virtudes sejam priorizadas por um estudioso da contabilidade nacional belga e que as mesmas não o sejam pela biógrafa de Ranke. Mais especificamente, isto levanta a questão sobre quando e com que motivos alguém pode argumentar que ambos os historiadores fazem uma contribuição valiosa, desejável e apropriada para a compreensão do passado, mesmo que eles atribuam pesos distintos para virtudes distintas.

Ao equiparar "conduta justificada" a "contribuições valiosas, desejáveis e pertinentes para a compreensão do passado", gostaria de ser entendido não somente como alguém que está empregando justificação num sentido mais amplo do que o de costume na epistemologia, mas também como alguém que se dissocia de abordagens fundacionalistas da justificação. Dizer que os historiadores têm justificação para privilegiar certas virtudes sobre outras não implica que tal ato de privilegiar esteja justificado a ponto de produzir conhecimento justificado do passado. Dado que eu não avalio desejo e pertinência em termos de conhecimento justificado, mas em termos de valor das contribuições para a compreensão do passado, o padrão que utilizo pode ser bem descrito como nãofundacionalista e contextual. Não é fundacionalista na medida em que o que conta como uma contribuição valiosa para a compreensão do passado depende não somente da habilidade para dar sentido para o corpus documental, mas também da habilidade para fazer avanços em relação à bibliografia especializada já existente. Além disso, o padrão é contextual na medida em que avanços dependem do estado da arte, isto é, da situação (historicamente contingente) na qual o historiador se encontra. E ainda, como devo explicar mais adiante, 
a despeito da sua alta sensibilidade para contextos, o padrão que utilizo para avaliar pertinência também é não-relativista, no sentido de que a biógrafa de Ranke e o estudioso da contabilidade nacional belga, uma vez que queiram fazer uma contribuição valiosa para a compreensão do passado, não são livres para escolher as virtudes que quiserem.

Num certo sentido, então, este artigo tenta reconciliar a ênfase historicista na relação entre as virtudes intelectuais e os contextos históricos em que se formam, de um lado, com uma abordagem não relativista da pesquisa histórica acadêmica, do outro. Argumentarei que os dois historiadores no centro dos nossos estudos-de-caso têm boas razões para empregar diferentes hierarquias de virtudes intelectuais, uma vez que estão envolvidos no que eu chamo de situações historiográficas diferentes. Da mesma forma, em reação às tradições historiográficas significativamente diferentes daquilo que, atualmente, pode ser reconhecido como erudição histórica sólida, defenderei que os historiadores têm todas as justificativas para buscar quaisquer metas intelectuais que desejarem, mas que, como historiadores acadêmicos, não estarão justificados caso priorizem uma destas metas em detrimento da compreensão histórica - a meta intelectual que considero como fundamental para a erudição histórica.

\section{$\mathbf{I}$}

Vamos começar com a questão sobre em que medida a biógrafa de Ranke e o historiador da economia partilham do mesmo conjunto de virtudes intelectuais. Partindo do princípio de que ambos fazem o que for necessário para se destacarem em seus trabalhos, os conjuntos das virtudes que exercitam estão propensos a se sobrepor. Entre outras coisas, ambos historiadores farão o seu melhor para serem exatos, no sentido de estarem atentos à precisão. Ambos tentam ser justos, no sentido de considerar de maneira ponderada todas as fontes e todos os fatores relevantes. Ambos também tentam pôr em prática a virtude da coragem intelectual, algo indispensável para abordar o papel do providencialismo luterano na filosofia da história de Ranke, bem como para estimar a fatia de mercado das companhias horticultoras flamengas no respectivo setor da economia belga (na ausência de outros dados exatos). Ao mesmo tempo, estas virtudes parecem ser diferentes. Compreender os aspectos intrincados do caráter de Ranke exige uma dose de empatia, caridade e humildade, algo que não é normalmente necessário quando se trata de calcular perdas e ganhos monetários. Da mesma forma, sintetizar um corpo significativo de literatura secundária exige a habilidade para negociar um equilíbrio delicado entre autonomia e generosidade com relação aos autores que já se dedicaram ao mesmo tema, algo com o que o primeiro especialista em horticultores flamencos não precisa se preocupar.

Isto poderia implicar, então, que os conjuntos de virtudes empregados pelos nossos dois historiadores não são idênticos? Tal conclusão seria precipitada. Pois mesmo que o historiador da economia não tenha que capturar as sutilezas do caráter de uma pessoa, nem tenha que se referir a uma pilha de literatura secundária, isto não significa que ele possa se permitir ignorar virtudes tais como a empatia, a caridade e a generosidade. Ele precisa, por exemplo, de uma 
certa quantidade de empatia para dar sentido a dados que foram lançados de maneira amadora e confusa. Da mesma forma, uma dose saudável de humildade o prevenirá de confiar de modo desmedido no significado e na fiabilidade das suas generalizações estatísticas. Assim, o fato de que historiadores diferentes, em situações diferentes, atribuam pesos distintos para virtudes distintas não confirma a conclusão de que seus conjuntos de virtudes seriam não-idênticos. As diferenças entre eles talvez não sejam de tipo, mas antes de grau e ênfase.

Será que alguém poderia, então, argumentar que as tarefas enfrentadas pela biógrafa de Ranke e pelo especialista em agricultura são tão diferentes a ponto de requererem diferentes hierarquias de virtudes intelectuais? Enquanto a lista de virtudes necessárias para a biógrafa de Ranke pode começar pela empatia e pela firmeza, as virtudes mais importantes para o historiador da economia podem ser a precisão e a atenção. Isto significa que os nossos dois historiadores devem priorizar algumas virtudes sobre outras, com o fito de exercitar as virtudes mais importantes para a sua pesquisa com mais dedicação e num grau mais elevado do que aquelas menos cruciais para a tarefa a ser desempenhada. Calcular os lucros e perdas monetárias de um horticultor flamengo é uma tarefa tão diferente de compreender a mente de um historiador alemão do século XIX, que um historiador que se dedique ao primeiro projeto precisa priorizar virtudes intelectuais diversas daquelas que são mais importantes para o historiador envolvido no segundo projeto.

Sob quais circunstâncias, então, seria justificado priorizar certas virtudes 30 sobre outras? O que diferencia as tarefas dos dois historiadores a ponto de justificar, na execução de cada uma delas, a atribuição de pesos distintos para virtudes distintas? Eu gostaria de sugerir que hierarquias de virtudes intelectuais dependem de situações historiográficas, isto é, da interação entre (1) o gênero da escrita, (2) o problema de pesquisa do historiador, e (3) o estado da literatura especializada. Gêneros de escrita incluem o artigo monográfico, baseado em pesquisa extensiva de fontes primárias; o balanço bibliográfico, que analisa as pesquisas recentes em um campo específico de investigação; e o manual, que sintetiza o estado atual dos estudos em um tema ou período em particular. Por mais rudimentar que seja, esta tipologia - uma mais detalhada seria desejável - ilustra que as hierarquias de virtudes intelectuais não podem ser idênticas em todas as circunstâncias. O autor de um manual, normalmente, precisa ter um grande poder de síntese - o que pode corresponder à virtude da firmeza intelectual - do que o autor de um artigo baseado em pesquisa detalhada. Além disto, a questão que move a pesquisa do historiador, ou o problema que ele ou ela pretende ajudar a resolver, desempenha um papel crucial. Um capítulo sobre a questão "a que horas os assassinos de Júlio César se reuniram nos Idos de Março, em 44 A.C.?" se ligará a um tipo de pesquisa diferente do que um livro sobre "China, Europa e a formação da economia mundial moderna" (RAMSAY 2008; POMERANZ 2000). Enquanto o primeiro projeto busca resolver um problema factual ("quando"), a segunda pesquisa remete a tipos complexos de explicação ("por quê"). Da mesma maneira, o historiador que tenta reconstruir a contabilidade nacional belga ("quanto") deve realizar um trabalho intelectual 
diferente do que é realizado pela sua colega que busca compreender os aspectos intrincados da personalidade de Ranke ("como era o ser humano").

Finalmente, o estado da arte, da literatura secundária existente sobre um dado assunto, também é um elemento constitutivo das situações historiográficas. Como é diferente a tarefa da nossa biógrafa de Ranke, cuja pesquisa precisa se debruçar sobre dezenas de antigas monografias e centenas de artigos já publicados sobre o "pai da historiografia moderna", se comparada com o trabalho pioneiro que o nosso segundo historiador conduz nos arquivos dos negócios flamengos. Enquanto aquela está, explicitamente ou não, em diálogo constante com várias interpretações alternativas, este não tem o benefício nem o fardo representados por um tal corpus de literatura especializada. Quando eu defendo a ideia de que nossos dois historiadores se encontram em diferentes situações historiográficas, este termo se refere a uma interação entre gênero, problema de pesquisa e o estado da arte, interação esta que funciona de maneira distinta para cada um destes historiadores.

O meu argumento, portanto, é o de que as diferentes hierarquias de virtudes intelectuais se justificam em razão das diversas situações historiográficas. Dependendo da sua situação historiográfica, os historiadores deverão priorizar certas virtudes perante outras, ou concentrar-se em algumas virtudes mais do que em outras. Os historiadores têm razões para fazê-lo, porque não é possível aprimorar a compreensão do passado sem que haja uma sintonia fina entre as suas virtudes e a sua situação. Assim, aprimorar a compreensão histórica depende, no final das contas, do gênero, do problema da pesquisa, e do estado da arte. Não se pode especificar o quanto se aperfeiçoou o conhecimento histórico sem prestar atenção às demandas de uma situação historiográfica específica. Historiadores que tentam contribuir para uma melhor compreensão do passado não somente podem priorizar virtudes à luz da sua situação historiográfica. Na verdade, eles necessariamente têm de proceder assim. Hierarquias diferentes de virtudes intelectuais tornam-se justificadas em função das diferentes situações historiográficas. ${ }^{3}$

\section{II}

Tudo isto sugere pelo menos duas razões pelas quais seria inapropriado abordar os nossos historiadores com um questionário em mãos, checando quais virtudes eles necessitam e quais eles não necessitam. Em primeiro lugar, a prática da virtude intelectual - ou virtude moral, no caso - jamais pode ser

\footnotetext{
${ }^{3}$ Não defendo a ideia de que diferentes hierarquias intelectuais se justificam tendo como base os interesses ou preferências pessoais do historiador, embora tais fatores geralmente exerçam uma influência considerável sobre como a pesquisa histórica acadêmica é conduzida. Isto, por sua vez, não retira a legitimidade dos historiadores que seguem as suas preferências ou interesses, mas, antes, permite reconhecer que tais preferências ou interesses não contribuem para a justificação da compreensão histórica. Em outras palavras: mesmo quando os historiadores, como ocorre normalmente, no seu trabalho, são fortemente influenciados por seus interesses e preferências pessoais, somente as suas situações historiográficas podem justificar a hierarquia de virtudes intelectuais que se estabelece. Em termos mais práticos: quando um resenhista julga que os autores de uma certa publicação deveriam ter tido mais cautela e tato nas suas explicações de eventos passados, este julgamento está baseado no que os autores deveriam ter feito a partir da sua situação historiográfica - e não na questão de se os autores apreciam virtudes como o tato e a cautela, ou se teriam capacidade para tal. Isto implica que o resenhista opera a partir da premissa de que as hierarquias de virtudes intelectuais não podem ser justificadas tendo como base interesses ou preferências pessoais.
} 
descrita em termos binários ("sim" ou "não"). Se é verdade que a biógrafa de Ranke e o historiador da economia têm muitas virtudes intelectuais em comum, mas empregam estas virtudes de maneira diferentes - cada um do seu jeito, priorizando certas virtudes em relação a outras, de acordo com as suas respectivas situações historiográficas - , então, em primeiro lugar, dizer que os dois historiadores são justos e precisos não é dizer muita coisa. Seria mais revelador aprender como eles praticam estas virtudes, cada um à sua maneira, na sua própria situação. Isto implica, em segundo lugar, que a abordagem-questionário inevitavelmente resulte em descrições "ralas" do comportamento intelectual virtuoso. Ralas são as descrições que não prestam atenção às demandas específicas que se colocam aos historiadores nas situações historiográficas em que se encontram. Descrições "densas", por contraste, tentam especificar o que, numa dada situação historiográfica, os historiadores precisam fazer para aperfeiçoar a sua compreensão do passado (quais virtudes intelectuais são mais cruciais em sua situação e com quanto esforço estas virtudes devem ser praticadas com o objetivo de se obter uma compreensão adequada do passado). Por isso, somente descrições densas podem explicar a diferença entre a biógrafa de Ranke e o historiador especializado em horticultura, no que diz respeito às suas virtudes intelectuais. ${ }^{4}$

Mais uma razão - a terceira - para rejeitar a abordagem por questionário é que o comportamento virtuoso jamais é uma questão de "ou isto, ou aquilo", mas sempre uma questão de grau. Cuidado, por exemplo, não é algo que 32 alguém possui ou não, mas, antes, uma virtude que alguém pode praticar em maior ou menor medida. Ninguém é perfeitamente cuidadoso ou completamente negligente, da mesma maneira que não há ninguém que seja ou perfeitamente bom ou totalmente desprovido de bondade. Claro que alguém pode se esforçar em ser mais cuidadoso, no sentido de praticar uma virtude em particular com mais afinco do que antes, da mesma forma como alguém pode se tornar uma pessoa moralmente melhor. Virtudes são medidas em uma escala, mais do que por um questionário limitado a "sim" e "não". Ao invés, portanto, de perguntar se os historiadores exercem a virtude da cautela, devemos perguntar: o quão cautelosos eles são?

Por essas três razões, não estou particularmente interessado na questão sobre se há virtudes intelectuais "universais", isto é, se há virtudes intelectuais que todos os historiadores devem praticar. Mark Day, por exemplo, defende a precisão e a consensualidade (ou a acurácia e a justiça, para usar a minha terminologia) como as duas virtudes mais importantes para os historiadores (DAY 2008, p. 42). Embora a sua investigação sobre que virtudes os historiadores devem prezar resulte numa lista impressionantemente longa, Day condensa deliberadamente as suas descobertas empíricas num duplo imperativo: "maximize o escopo do material abordado, sem prejuízo ao sentido de unidade e maximize a precisão sem prejuízo da clareza" (DAY 2008, p. 24). Não se sabe, porém, qual seria o propósito de identificar tais virtudes intelectuais

\footnotetext{
${ }^{4}$ A terminologia, é claro, deve ser creditada a Clifford Geertz (1973).
} 
"universais" - aquelas exigidas por todos os historiadores em todas as situações historiográficas - quando as diferenças entre nossos dois historiadores, no que diz respeito às suas virtudes intelectuais, não parecem residir no tipo de virtudes que eles devem praticar, mas, antes, na maneira ou no grau com os quais eles devem praticá-las. Além disso, de que serve apresentar a precisão e a consensualidade como sendo as virtudes mais essenciais ao historiador sem especificar as posições ocupadas por essas virtudes nas hierarquias de virtudes intelectuais? Não se pode presumir que estas hierarquias sempre são, em todas as situações, encimadas por virtudes como a acurácia e a justiça. Enquanto o historiador especialista em horticultura pode precisar dar prioridade à primeira em relação à segunda, o reverso talvez valha para o biógrafo de Ranke.

Com base no que foi exposto, alguém pode argumentar que os historiadores precisam, universalmente, não de uma virtude, mas de uma "meta-virtude". O que os historiadores necessitam, em todas as situações historiográficas, é uma certa dose de phronesis, que Ihes permita perceber quais são as demandas postas a cada situação. Phronesis, ou o ato de invocar a palavra correta na hora e no lugar certos, é o que os historiadores necessitam quando precisam estabelecer hierarquias de valores intelectuais sintonizadas com a situação em que estão. E é precisamente na medida em que as diferentes situações historiográficas se ligam a diferentes exigências que os historiadores precisam da meta-virtude aristotélica da phronesis- isto é, da virtude que Ihes ajuda a discernir o que é necessário, em cada uma destas situações, para se fazer uma contribuição para uma melhor compreensão do passado. ${ }^{5}$

\section{III}

Imagine agora que a população que compõe o experimento, em vez de se restringir aos dois acadêmicos há pouco mencionados - o biógrafo de Ranke e o historiador imerso em registros comerciais flamengos -, abarca também historiadores de outras épocas e regiões, como são Gregório de Tours, o bispo galo-romano conhecido pela sua Historia francorum, e SimaQian, também conhecido como "o pai da historiografia chinesa", cujos Shiji, ou Relatos do magnífico historiador apareceram por volta de 90 a.C. ${ }^{6}$ Em que medida esse acréscimo da população sob investigação irá afetar as conclusões já alcançadas?

Especialistas em historiografia não tardarão em assinalar que esses historiadores se dedicaram a formas de investigação histórica que são dificilmente comparáveis às que se praticam no mundo acadêmico moderno. Em se tratando de virtude intelectual, poderiam argumentar que historiadores da Antiguidade

\footnotetext{
${ }^{5}$ Sobre a phronesis em Aristóteles, ver Moss (2011). Sobre o tato como "uma sensibilidade para situações e para a maneira de lidar com elas, para o que o conhecimento de princípios gerais não basta", ver também Gadamer (1998, p. 16).

${ }^{6}$ Ao classificar ambos os autores como "historiadores", não tenho a intenção de lhes atribuir qualquer outra qualidade em comum a não ser a de que ambos estudaram o passado. Por razão semelhante, um levantamento global sobre o pensamento e a prática históricas, recentemente realizado, identifica os historiadores como aquelas pessoas "que registraram ou representaram o passado, seja por motivos ligados a interesses pessoais, seja em razão de propósitos sociais ou políticos mais alargados". Essa definição inclui contadores de estórias da África subsaariana, além daqueles que na América andina pré-colombiana costumavam usar o quipu como um dispositivo para registrar memórias comunais. Ver: Woolf (2011, p. 5).
} 
e da Idade Média, cada um ao seu modo, se comprometiam com ideais de individualidade e erudição, além de noções de virtuosidade intelectual, que hoje em dia apenas poucos historiadores aceitariam. Por essa razão, eles podem sugerir que aquilo que conta como comportamento intelectualmente virtuoso se altera em função do tempo e do espaço. Afinal de contas, nenhum acadêmico contemporâneo poderá concordar com SimaQian quando este assume que a fortuna e os infortúnios dos povos seriam explicáveis por referência à noção confuciana de uma ordem cósmica (dao) e que, por conseguinte, os historiadores teriam de possuir a habilidade de perceber se os povos terão ou não vivido em consonância com o dao (MUTSCHLER 2007, p. 197). Do mesmo modo seria difícil encontrar um defensor contemporâneo da visão de Gregório de que a fé cega naquilo que a Bíblia ensina em matéria de história é uma virtude que contribui para o bom entendimento do passado (BEUKELAAR 1994, p. 52-54). Portanto, falando empiricamente, o que conta como sendo um comportamento intelectualmente virtuoso não está gravado em pedra: diferentes tradições nutrem diferentes percepções quanto ao assunto.

A questão mais importante é, então, em que medida SimaQian e Gregório tinham justificativa para empregar virtudes, ou conjuntos de virtudes intelectuais, que diferem daquelas usadas pelo nosso biógrafo de Ranke ou pelo nosso historiador da economia. Penso que essa é uma questão de grande relevância porque ela parece nos colocar diante do desagradável dilema de termos que escolher entre (1) a ideia de que diferentes padrões de virtuosidade 34 intelectual podem coexistir de maneira legítima - uma ideia que muitas vezes é adotada implicitamente pelos historiadores da historiografia - e (2) o argumento de que SimaQian e Gregório não podem ser qualificados como historiadores intelectualmente virtuosos por estarem fora dos padrões que para nós definem a virtuosidade intelectual. A primeira ideia dificilmente pode ser reconciliada com o meu argumento de que o que pode variar de maneira justificada de uma situação à outra são apenas as hierarquias de virtudes intelectuais. Além disso, parece também abraçar um relativismo com respeito ao tema da virtuosidade intelectual, o qual provavelmente não resistiria a um exame mais minucioso (BEVIR 1999, p. 106-124). A segunda ideia, contudo, não é muito mais atraente. Parece deixar de lado que aquilo que motiva os historiadores em primeiro lugar, ou seja, a possibilidade de aprendermos com aqueles que viveram antes de nós, de nos enriquecermos a nós próprios com as percepções deles e, assim, superarmos alguns dos nossos defeitos e limitações. Em outras palavras, será que, neste segundo caso, não estamos assumindo aprioristicamente que temos uma melhor compreensão de virtuosidade intelectual do que SimaQian ou Gregório tinham? Sendo assim, por que nos interessaríamos pelas visões de virtuosidade deles? E, por outro lado, se evitarmos julgar, abrindo-nos para o que os historiadores chamam de "alteridade" ou "estranheza" do passado, como faríamos para não adotar tacitamente uma posição relativista similar à que foi explicada em (1)?

De modo a escapar desse dilema, gostaria de introduzir uma outra categoria conceitual. Enquanto os dois historiadores discutidos na seção anterior 
trabalhavam meramente em situações historiográficas distintas, empregando consequentemente diferentes hierarquias de virtudes intelectuais, o grupo mais heterogêneo de historiadores que agora atrai a nossa atenção também nos coloca defronte a diferentes hierarquias de metas intelectuais (intelectual goods). Metas (goods) apontam para as finalidades que dirigem as investigações intelectuais, ou, no contexto deste artigo, para os bens que a pesquisa histórica supostamente deve distribuir (ROBERTS; WOOD 2007, p. 32-58). Um exemplo óbvio dessas metas é a compreensão histórica, algo que pode ser definido de maneira algo imprecisa como um olhar para uma ordem de coisas do passado. Historiadores cujo objetivo primário é compreender algo historicamente procuram incrementar a sua habilidade para falar do passado de modo fidedigno. A sua preocupação principal não é atingir juízos morais, prazer estético, ou reconhecimento social, mas compreender como o mundo era antigamente. ${ }^{7}$

A compreensão, no entanto, não é a única meta associada à investigação histórica. Isso se torna evidente quando consultamos o Shiji de SimaQian provavelmente o mais influente texto de história já escrito (WOOLF 2011, p. 63). Se tomarmos o autor ao pé da letra, a sua meta mais importante era demonstrar, com meios históricos, a legitimidade do dão confuciano. Como explica um especialista em historiografia chinesa, SimaQian tentou continuamente "dar à tradição uma unidade confuciana organizada", para, assim, ilustrar que o "caminho do céu" é sempre adequado e justo (DURRANT 1995, p. 27). Uma vez que nem todos os eventos e situações discutidas no Shiji correspondem bem àquilo que o confucionismo tradicionalmente entende como o caminho do céu, aparece no Shiji uma tendência para a "teodiceia", isto é, para dar explicações sobre por que o caminho do céu nunca é injusto. Portanto, a meta perseguida por SimaQian não era compreender o passado sob uma ótica confuciana, nem era compreender o dao enquanto tal. O que ele buscava, antes de mais nada, era uma justificação para o caminho do céu perante as aparentes incompreensibilidades da história humana. Além disso, SimaQian tinha em vista contribuir para aquilo que se poderia chamar de preservação do passado. Ele registrava eventos pretéritos, numa escala que não pode ser comparada com a dos seus antecessores, "de modo a prevenir que o passado caia para sempre na escuridão" (DURRANT 1995, p. 7). Um tal ímpeto para registrar eventos não apenas respondia ao propósito de compreender o passado, mas também, e mais essencialmente, preenchia a necessidade confuciana de honrar os ancestrais e de impedir que os nomes destes caísses no esquecimento. Em terceiro lugar, o Shiji pretendia servir a uma finalidade didática ao tratar personagens e situações históricas como exemplos morais - ainda que, como afirma Stephen W. Durrant, tal finalidade amiúde fosse mitigada pelo apetite insaciável do autor por histórias bem amarradas, algo que Ihe permitiu criar "um caleidoscópio de personagens

\footnotetext{
7 Por conveniência, eu emprego aqui "compreensão" como uma categoria abrangente que vale tanto para verstehen quanto para erklären - termos com os quais historiadores e teóricos da história têm habitualmente definido quais são as metas da investigação histórica. Ver D'Oro (2009). Não vou aqui tentar resolver o problema de como a compreensão se relaciona com o conhecimento. Note-se apenas que a primeira é normalmente considerado como pressuposto do segundo e o segundo é considerado uma extensão da primeira. Ver, por exemplo, Kvanvig (2003, p. 185-203) e Riggs (2003).
} 
difíceis de classificar e de converter em exemplos inequívocos" (MUTSCHLER 2007, p. 199-200; DURRANT 1995, p. 143).

Observações parecidas podem ser feitas sobre a Historia francorum, ou História dos francos, escrita por Gregório de Tours no final do século VI. Que metas intelectuais Gregório tinha em vista? Para além da compreensão histórica, ele claramente esperava obter uma espécie de orientação temporal, ou seja, uma ideia acerca de onde estaria a humanidade dentro da linha do tempo que vai desde a criação até o juízo final. Quase todos os capítulos do seu livro se dedicam a contar o número de anos passados desde Adão e Eva, para que o leitor venha a saber quantos anos faltam para que se completem os 6.000 anos concedidos por Deus à história humana. Mesmo que tal orientação obviamente carecesse de elementos relacionados com a compreensão, Gregório, que era, lembremos, bispo, realizava os seus cálculos com um propósito mais pastoral em mente ("para aqueles que estão perdendo as esperanças, à medida que veem o fim do mundo a chegar cada vez mais perto") (GREGÓRIO DE TOURS 1974, p. 67). Para ele, portanto, orientação temporal não era em primeiro lugar uma questão de compreensão histórica, mas uma questão de natureza religiosa, ligada à garantia da salvação. Tal como SimaQian, Gregório também concedeu um valor considerável à função didática da historiografia. "Tenho de dedicar muito do meu espaço às querelas entre os perversos e os justos", afirmou ele, para nas páginas seguintes ressaltar de modo estridente como aos perversos está destinada à punição eterna, enquanto os que seguem Cristo reinarão em 36 glória (GREGÓRIO DE TOURS 1974, p. 63). A educação da audiência era um item claramente importante na lista de metas intelectuais de Gregório. ${ }^{8}$

\section{IV}

Como esses exemplos mostram, metas intelectuais normalmente aparecem no plural. Isso vale não apenas para historiadores que atuaram em épocas que hoje nos parecem longínquas. Pode ser, por exemplo, que o estudioso de Ranke não apenas queira ganhar uma compreensão detalhada da vida e da obra do historiador alemão. Ele pode querer aprender com Ranke sobre como ser um bom historiador. No espírito do famoso comentário de Burckhardt, de que cabe à investigação histórica "tornar-nos mais sábios (para sempre), em vez de apenas mais astutos (para a próxima vez)" (citado por GOSSMAN 2000, p. 272), ele pode querer melhorar-se a si próprio por meio da reflexão contínua sobre uma figura tão grandiosa e complicada quanto a de Ranke. Ou, alternativamente, pode querer chegar a algum tipo de avaliação sobre o valor relativo das realizações de Ranke. Pode, então, tomá-las como exemplo de uma erudição intelectualmente virtuosa; pode ainda tentar se dissociar das premissas eurocêntricas que subjazem à maior parte da obra de Ranke.

Eu não vejo motivos para que qualquer uma dessas metas intelectuais seja descartada como uma meta ilegítima. Quem quer que queira confinar a investigação histórica à procura da compreensão histórica, quem quer que

\footnotetext{
${ }^{8}$ Sobre esse tipo de metas intelectuais na historiografia medieval, ver Schmale (1985, p. 143-164).
} 
despreze o desejo de avaliar, julgar, aprender com o passado, tão comum entre os historiadores, rejeita automaticamente muito daquilo que dá certo na pesquisa histórica. Eu estou, portanto, preparado para aceitar que existe uma variedade de metas intelectuais (para não falar de metas não-intelectuais, como obter reconhecimento pessoal, ascender na carreira, ou ganhar dinheiro).$^{9} \mathrm{E}$ estou preparado para defender que os historiadores podem, legitimamente, correr atrás de qualquer uma dessas metas intelectuais ou não-intelectuais. Rejeito, contudo, a ideia de que todas essas metas sejam igualmente significativas. Não penso que os historiadores com pretensão à seriedade acadêmica estejam livres para priorizar a meta que bem quiserem (por exemplo, para colocar a aprendizagem com o passado à frente da compreensão). Por isso, discordo do argumento relativista de que, do ponto de vista da erudição histórica, o Shiji e a Historia francorum são tão aceitáveis quanto uma moderna biografia de Ranke ou uma reconstrução da contabilidade nacional belga.

A chave para essa posição encontra-se na premissa de que existem hierarquias de metas intelectuais, da mesma maneira que há hierarquias de virtudes intelectuais. Compreender, aprender e julgar qualificam-se como metas intelectuais, mas não funcionam como objetivos de igual importância para a erudição histórica. Pode-se imaginar que a estudiosa de Ranke priorize a aprendizagem (o que ela pode aprender com Ranke?) em vez do juízo valorativo (por que ela discorda dele?), ao mesmo tempo em que subordina ambos esses objetivos àquilo que ela corretamente identifica como sendo a mais importante meta da erudição histórica: a compreensão do passado. Outros historiadores, por trabalharem com temas que tendem a gerar objeções morais (escravidão, genocídio, etc.), podem ficar mais inclinados para julgar do que para aprender com o passado investigado, mas também subordinam esses dois objetivos à meta da compreensão histórica. Em contraste, o que faz com que SimaQian e Gregório de Tours apareçam, ao olhar moderno, como historiadores "não profissionais" é o fato de que eles parecem priorizar metas tais como a aprendizagem e o juízo, em detrimento da compreensão. Não é que eles pratiquem de modo insuficiente virtudes como o cuidado e a precisão - isto é, virtudes que estão no cerne da atitude crítica da qual a historiografia moderna frequentemente se orgulha. $\mathrm{O}$ problema é que eles deixam que a aprendizagem e o juízo valorativo ganhem precedência sobre a compreensão. Por mais que inegavelmente a compreensão histórica também se encontre entre as metas que eles procuram perseguir, a compreensão não aparece no lugar proeminente que ocupa nos nossos dois casos anteriores. Uma coisa está clara: o que distingue os nossos historiadores dos dias de hoje dos seus colegas da Antiguidade e da Idade Média não é que

\footnotetext{
9 Tais metas não-intelectuais são exemplos vívidos do que AlasdairMacIntyre chama de "metas ou bens externos" (externalgoods), ou seja, metas ou bens que derivam de uma prática cuja razão de ser é definida por uma "meta ou bem interno" (internalgood). O meu conceito de "metas intelectuais" é, entretanto, mais abrangente do que o conceito de "metas internas" de MacIntyre. Ainda que eu concorde com ele que as diferentes práticas humanas (como a da erudição histórica) normalmente sejam constituídas por apenas uma meta intelectual (como a compreensão histórica), não acho que tal circunstância transforme todas as demais metas em metas "externas". Quero crer que o desejo de aprender com o passado é menos externo para a prática da erudição histórica do que outras metas como, por exemplo, progredir na carreira ou ganhar dinheiro. Ver Macintyre (1981).
} 
aqueles, diferentemente destes, se dediquem exclusivamente à compreensão do passado. Argumentar assim implica negligenciar o grau em que os historiadores de hoje também se aplicam, conscientemente ou não, em avaliar e julgar o passado que investigam. ${ }^{10} \mathrm{O}$ ponto crucial aqui é que a compreensão seja a prioridade número um nas suas hierarquias de metas intelectuais.

Ainda que nunca se possa fazer cumprir tais prioridades à força, acredito que as hierarquias de metas intelectuais têm necessariamente de ser encabeçadas pela meta da compreensão, quando se pretende que uma investigação histórica seja reconhecida como pesquisa erudita. A compreensão histórica é fundamental para a erudição histórica. Por tal razão, a compreensão deve receber prioridade sobre todas as outras metas intelectuais (e também as não intelectuais) para que uma investigação histórica se qualifique como erudição. Isso implica que outras metas apenas podem ser perseguidas legitimamente na medida em que não atrapalhem a busca do historiador pela compreensão. Toda vez que as metas intelectuais ameaçam a colidir umas com as outras - por exemplo, quando o propósito de fornecer esclarecimento moral parece incompatível com o objetivo de compreender um mundo no qual o claro e o escuro estão estreitamente entrelaçados - deve-se dar precedência à compreensão. Historiadores que eventualmente optem por outras maneiras de resolver um conflito como esse podem estar agindo de maneira legítima, mas ao fazê-lo deixam de estar fazendo um trabalho acadêmico ou erudito. 0 mesmo critério de demarcação permite com que os historiadores neguem ao Shiji e à Historiafrancorum o status de trabalhos históricos eruditos. Exatamente na medida em que esses trabalhos subordinam a compreensão histórica à prossecução de outras metas intelectuais, deixam de poder pretender ser exemplos de trabalhos acadêmicos.

Perceba que nada disso quer dizer que os historiadores que priorizem outras metas que não a compreensão estejam a dedicar-se a um trabalho ilegítimo. Não quero contestar a legitimidade de um trabalho histórico preparado de acordo com os modelos fornecidos por SimaQian ou Gregório. Apesar de um tal trabalho não se qualificar como uma contribuição para a erudição histórica, pode o mesmo aspirar ter, por exemplo, valor literário. Assim como o Shiji hoje pode, com proveito, ser lido como um clássico literário (DURRANT 1995, p. 117), ${ }^{11}$ um trabalho atual nele inspirado pode almejar fins intelectuais virtuosos distintos da compreensão. De fato, um romance histórico como Terra d'água (Waterland), de Graham Swift é uma realização intelectual de primeira linha precisamente, porque, não muito diferentemente do Shiji, ousa subordinar a compreensão histórica (tal como definida acima) a uma reflexão sobre coisas como a natureza das tradições e a margem de manobra

\footnotetext{
10 Mark Day diferencia algumas formas específicas de "relação com o passado" (epistêmica, preservadora, dialógica e prática). Mesmo que se possa discordar de Day quanto à quantidade e à natureza dessas relações, é inegável que ele identifica um aspecto importante ao afirmar que "a relação crítico-epistêmica como o passado está envolvida nas outras formas de relação com o passado" (DAY 2008, 9).

11 "Frequentemente revisitamos os Registros do historiador [o Shiji, NT], porque este texto é tão difícil e inextrincável como a própria vida. As nuvens no espelho de SimaQian correspondem aos padrões de um ser humano completo e intrincado; são as mesmas nuvens que, de um jeito ou de outro, nos incomodam a todos nós (DURRANT 1995, p. 147).
} 
de que as pessoas dispõem para se libertar de crenças e práticas herdadas. A quem quer que queira compreender a história dos Fens - a região ao leste da Inglaterra na qual Swift situa a sua narrativa - recomenda-se que procure uma monografia acadêmica. Mas um leitor que esteja à procura, por exemplo, de uma visão sobre as peculiaridades humanas fará bem em passar algumas noites na companhia de Terra d'água (SWIFT 1983). ${ }^{12}$ Portanto, a precedência da compreensão histórica sobre outas metas intelectuais não é absoluta; serve meramente como um critério de demarcação entre as do passado que têm pretensão acadêmica e as que não podem ter. Explica, todavia, porque os historiadores de hoje corretamente rejeitam o Shiji e a Historia francorum como contribuições sérias à erudição histórica.

Por último, gostaria de assinalar que não é possível especificar de antemão que tipo de finalidade deveria ocupar a segunda, a terceira, ou a quarta posições na hierarquia de metas intelectuais do historiador, nem tampouco os motivos à luz dos quais tais hierarquias podem ser justificadas. Dos historiadores que se dedicam à pesquisa erudita pode-se esperar apenas que deem prioridade à compreensão, de maneira a evitar que a persecução de metas intelectuais alternativas não comprometa aquele objetivo fundamental. Por sorte, contudo, esse requisito é forte o suficiente para permitir que os historiadores eruditos se dissociem de SimaQian, Gregório de Tours, ou qualquer outro historiador que priorize, por exemplo, a aprendizagem ou o juízo em detrimento da compreensão. É forte o suficiente para colocar em causa a ideia relativista de que a historiografia antiga ou medieval é simplesmente tão boa quanto a historiografia acadêmica contemporânea. Contrapõe-se a esse relativismo ao privilegiar a compreensão histórica em detrimento de outras metas intelectuais. Ainda que possa haver diferentes hierarquias de metas intelectuais, é característica fundamental da erudição histórica a precedência da compreensão sobre as demais metas, não podendo essa compreensão ser obstaculizada pela vontade de aprender com o passado ou pelo desejo de julgar os méritos relativos daqueles que vieram antes de nós.

\section{V}

Ambas as formas de hierarquia acima discutidas - hierarquias de virtudes intelectuais e hierarquias de metas intelectuais - servem ao propósito de conciliar uma descrição não relativista da erudição histórica com a percepção historicista de que o comportamento intelectual virtuoso se forma dentro do seu contexto histórico. O primeiro tipo de hierarquia contribui para tal propósito ao rejeitar um modelo uniformizado de virtuosidade histórica em favor de um modelo que permite variações significativas no peso que os historiadores conferem a cada uma das virtudes intelectuais de que lançam mão para promover uma melhor compreensão do passado. Além disso, essas diferenças não são relacionadas aos interesses e preferências pessoais dos historiadores, mas antes às suas situações historiográficas, de tal modo que as

\footnotetext{
12 Agradeço a Madeleine Karsten por me ter exortado a ler esse maravilhoso romance.
} 
hierarquias de virtudes intelectuais, em vez de serem meramente arbitrárias, passam a ser vistas em função das demandas que cada situação impõe ao historiador. Da mesma forma, o segundo tipo de hierarquia deixa espaço para que diversas metas intelectuais sejam perseguidas - inclusive aquelas que são preferidas por historiadores que trabalham dentro de tradições que hoje dificilmente seriam reconhecidas como erudição histórica -, mas ao mesmo tempo cria uma barreira de contenção contra o espectro do relativismo, uma vez que trata a compreensão histórica como uma meta intelectual prioritária quando o assunto é pesquisa histórica erudita.

Por essa razão, a posição que é advogada no presente texto não é uma posição fortemente historicista. Historicismo forte corresponderia à ideia de que a investigação histórica "é total e necessariamente determinada pela realidade finita da circunstância histórica". Ao operar a partir do pressuposto da "paroquialidade total e inevitável da razão", o historicismo forte exclui a possibilidade de definir a erudição histórica de modo situacionalmente transcendente (PAGE 1995, p. xi, 3). Apesar de a minha posição permanecer simpática ao impulso historicizante que perpassa a maior parte dos trabalhos recentes de história da historiografia, eu rejeito um tal historicismo forte em nome de uma descrição não relativista da erudição histórica. Afirmo serem não relativistas tanto o meu argumento de que a compreensão histórica é fundamental para a erudição histórica quanto a conclusão de que a meta da compreensão deve ter prioridade sobre as demais metas (pelo menos no plano da erudição).

HO A minha posição pode então ser descrita como historicista em sentido fraco. O historicismo fraco é historicista na medida em que rejeita descrições de comportamentos intelectualmente virtuosos que sejam "magras" ou inespecíficas do ponto de vista situacional, e em que aponta para as demandas intelectuais encaradas pelos historiadores em diferentes situações historiográficas. Além disso, é também historicista uma vez que aceita como um dado da realidade que os historiadores frequentemente se colocam metas que são distintas da compreensão histórica, e porque, desde um ponto de vista normativo, autorizaos a assim proceder. Todavia, ao endossar a tese forte de que a compreensão histórica deve ser a prioridade número um de qualquer historiador que queira realizar um trabalho acadêmico, o referido historicismo fraco deixa de trazer consigo as implicações relativistas típicas do historicismo forte. Para resumir: o historicismo fraco adota uma postura categórica quanto àquilo que qualifica um trabalho de história como um trabalho erudito ou acadêmico, ao mesmo tempo em que admite de modo mais generoso que o comportamento intelectualmente virtuoso é marcado pelos contextos históricos. Será presunçoso pensar que, nesse historicismo fraco, aumentam as probabilidades para que os historiadores da historiografia interessados em descrições densas de comportamentos intelectualmente virtuosos e os teóricos da história desejosos de evitar o espectro do relativismo se aproximem uns dos outros? ${ }^{13}$

\footnotetext{
${ }^{13}$ Agradeço a Mark Bevir e Allen R. Dunn pelos comentários que fizeram a uma versão preliminar deste artigo.
} 


\section{Referências bibliográficas}

ALSTON, William P. Concepts of epistemic justification. In: ALSTON. Epistemic Justification: Essays in the Theory of Knowledge. Ithaca: Cornell University Press, 1989, p. 81-114.

BEUKELAAR, Adriaan H. B. Historiography and Episcopal Authority in Sixth-Century Gaul: The Histories of Gregory of Tours Interpreted in their Historical Context. Göttingen: Vandenhoeck \& Ruprecht, 1994.

BEVIR, Mark. The Logic of the History of Ideas. Cambridge: Cambridge University Press, 1999.

DASTON, Lorraine; GALISON, Peter. Objectivity. New York: Zone Books, 2007.

DAY, Mark. The Philosophy of History: An Introduction. London: Continuum, 2008.

D'ORO, Giuseppina. Historiographic Understanding. In: TUCKER, Aviezer (org.).

A Companion to the Philosophy of History and Historiography. Chichester: Wiley-Blackwell, 2009, p. 142-151.

DURRANT, Stepehn W. The Cloudy Mirror: Tension and Conflict in the Writings of Sima Qian. Albany: State University of New York Press, 1995.

GADAMER, Hans-Georg. Truth and Method. New York: Continuum, 1998.

GEERTZ, Clifford. Thick Description: Toward an Interpretative Theory of Culture. In: The Interpreation of Cultures: Selected Essays. New York: Basic Books, 1973, p. 3-30.

GOSSMAN, Lionel. Basel in the Age of Burckhardt: A Study in Unseasonable Ideas. Chicago: University of Chicago Press, 2000.

GREGÓRIO DE TOURS. The History of the Franks. Harmondsworth: Penguin Books, 1974.

KNANVIG, Jonathan. The Value of Knowledge and the Pursuit of Understanding. Cambridge: Cambridge University Press, 2003.

MACINTYRE, Alasdair. After Virtue: A Study in Moral Theory. London: Duckworth, 1981.

MOSS, Jessica. 'Virtudes Make the Goal Right': Virtue and Phronesis in Aristotle 's Ethics. Phronesis, v. 56, p. 204-261, 2011.

MUTSCHLER, F. -H. Sima Qian and His Western Colleagues: On Possible Categories of Description. History and Theory, v. 46, n. 2, p. 194-200, 2007.

PAGE, Carl. Philosophical Historicism and the Betrayal of First Philosophy. University Park: Pennsylvania State University Press, 1995.

PAUL, Herman.The Scholarly Self: Ideals of Intellectual Virtue in NineteenthCentury Leiden. In: BOD, Rens; MAAT, Jaap; WESTSTEIJN, Thijs (orgs.). The Making of the Humanities. Amsterdam: Amsterdam University Press, 2012, p. 397-412. v. II. 
. Performing History: How historical scholarship is shaped by epistemic virtudes. History and Theory, v. 50, n. 1, 2011, p. 1-19, 2011 a.

. Distance and Self-Distanciation: Intellectual Virtude and Historical Method around 1900. History and Theory, v. 50, n. 4, 2011, p. 104116, 2011b.

PLANTINGA, Alvin. Warrant: The Current Debate. Oxford: Oxford University Press, 1993.

POMERANZ, Kenneth. The Great Divergence: China, Europe, and the Making of the Modern World Economy. London: Princeton University Press, 2000.

RAMSEY, John. At What Hour Did the Murderers of Julius Caeser Gather on The Ides of March 44 B.C.W. In: HEILEN, Stephan et al. (orgs.). In Pursuit of Wissenschaft: Festschrift für William M. Calder III zum 75. Geburtstag. New York: Georg Olms Verlag, 2008, p. 351-363.

ROBERTS, Robert C.; WOOD, W. Jay. Intellectual Virtues: An Essay in Regulative Epistemology. Oxford: Clarendon Press, 2007.

RIGGS, Wayne D. Understanding 'Virtue' and the Virtue of Understanding. In: DEPAUL, Michael; ZAGZEBSKI, Linda (orgs.). Intellectual Virtues: Perspectives from Ethics and Epistemology. Oxford: Clarendon Press, 2003, p. 203-226.

SCHMALE, Franz-Josef. Funktionen und Formen mittelalterlicher Geschichtsschreibung: Eine Einführung. Darmstadt: Wissenschaftliche Buchgesellschaft, 1985.

SMITS, Jan-Pieter, HORLINGS, Edwin; ZANDEN, Jan Luiten van. Sprekende cijfers! De historische nationale rekeningen van Nederland, 1807-1913. NEHA-Jaarboek, n. 62, p. 51-110, 1999.

SWIFT, Graham. Waterland. London: William Heinemann, 1983.

WOOLF, Daniel. A Global History of History. Cambridge: Cambridge University Press, 2011.

ZAGZEBSKI, Linda. Recovering Understanding. In: STEUP, Mathias (org.). Knowledge, Truth, and Duty: Essays on Epistemic Justification, Responsibility, and Virtue. Oxford: Oxford University Press, 2001, p. 235251. 